\title{
Medievalista
}

Online

$25 \mid 2019$

Número 25

\section{Os simbolismos dos animais com chifres em bestiários ingleses}

Dissertação de Mestrado em História Medieval apresentada à Faculdade de Ciências Sociais e Humanas da Universidade Nova de Lisboa, Maio de 2018. Orientação do Professor Doutor Bernardo Vasconcelos e Sousa e coorientação do Doutor Pedro Chambel

\section{Marcelo Cardoso Amato}

\section{OpenEdition}

\section{Journals}

Edição electrónica

URL: http://journals.openedition.org/medievalista/1783

DOI: 10.4000/medievalista.1783

ISSN: 1646-740X

\section{Editora}

Instituto de Estudos Medievais - FCSH-UNL

\section{Refêrencia eletrónica}

Marcelo Cardoso Amato, «Os simbolismos dos animais com chifres em bestiários ingleses »,

Medievalista [Online], 25 | 2019, posto online no dia 17 março 2019, consultado o 23 setembro 2020

URL : http://journals.openedition.org/medievalista/1783 ; DOI : https://doi.org/10.4000/medievalista 1783

Este documento foi criado de forma automática no dia 23 setembro 2020.

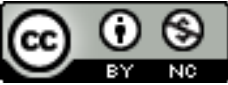

Mediavalista está licenciado com uma Licença Creative Commons - Atribuição-NãoComercial 4.0 Internacional. 


\section{Os simbolismos dos animais com chifres em bestiários ingleses}

Dissertação de Mestrado em História Medieval apresentada à Faculdade de Ciências Sociais e Humanas da Universidade Nova de Lisboa, Maio de 2018. Orientação do Professor Doutor Bernardo Vasconcelos e Sousa e coorientação do Doutor Pedro Chambel

\section{Marcelo Cardoso Amato}

\section{NOTA DO EDITOR}

Data recepção do artigo / Received for publication: 01-10-2018

\section{Introdução}

1 Desde tempos muito remotos que os chifres são encarados pela mentalidade do homem como símbolos. Provavelmente, a associação mais antiga relaciona-os com as fases da lua, justificada pela semelhança entre o formato dos chifres e o do satélite natural. Com o decorrer da História, os chifres se tornaram símbolos mais complexos. Possivelmente decorrente da observação do poder destrutivo destes elementos na natureza, os chifres passaram a estar simbolicamente associados ao poder e à força em diferentes tradições. Surgem como elementos apotropaicos, como na tradição hebraica, por exemplo, onde se encontrariam chifres em altares; como símbolos da abundância, lembrando a representação da cornucópia clássica; e, em diferentes culturas da Antiguidade, como símbolo da elevação e do poder espiritual, aludindo às figuras de Amón, o deus egípcio chamado no Livro dos Mortos de Senhor dos chifres; a Apolo-Karneios, representado com chifres de carneiro; a Shiva, que é habitualmente apresentado junto a um touro branco de nome Nandi, entre outros. Ao contrário do que se poderia supor, a ascensão e implementação do Cristianismo não significou a exclusão dos seus diversos simbolismos. Na Bíblia, os chifres integram metáforas, simbolizando a glória, a 
dignidade, o poder, a honra, a vitória, a liderança, a coragem, a proteção, a salvação, entre outros ${ }^{1}$.

Na vida do homem medieval é inquestionável a presença constante dos animais com chifres. Na medicina, por exemplo, não era incomum a utilização de chifres de cervos ou unicórnios nas receitas curativas. Uma taça feita com o chifre do unicórnio tinha o poder de neutralizar qualquer tipo de veneno, assim como o tinha a ingestão do pó feito a partir desse material ${ }^{2}$. Além da medicina, os chifres e os animais com chifres desempenhavam diversas funções na produção agrícola, nas dietas, nas vestimentas, na caça, na heráldica, entre outros. Dada a sua presença constante, estes animais são personagens também frequentes nas narrativas alegóricas. Parte-se do pressuposto de que o imaginário medieval se baseava na visão simbólico-alegórica do universo, na qual um animal, as suas características biológicas e os comportamentos se tornam um espelho que permite compreender melhor Deus e as suas mensagens. Nesse sentido, o gênero medieval mais importante para este estudo é o dos bestiários, manuscritos monásticos de caráter moralizante, produzidos principalmente entre os séculos XII e XIII, em Inglaterra e em França. Tais documentos foram compostos a partir de obras basilares como a Bíblia; História Natural de Plínio, o Velho (23-79), considerada a primeira enciclopédia da natureza; Physiologus (obra anônima do século II); De natura animalium, composta pelo sofista Cláudio Eliano (175-235); a Collectanea rerum memorabilium de Solino (séc. III); Etimologias, de Isidoro de Sevilha (560-636), entre outras.

\section{Os simbolismos dos animais com chifres}

3 Ao contrário do que se poderia supor, dada a constante vigilância contra o pecado durante a Idade Média e a construção da imagem do diabo - com chifres -, grande parte dos animais chifrudos carregam simbolismos positivos, ainda que diversos. É o caso, por exemplo, das narrativas do íbex e do antílope, que apresentam os chifres como elementos de luta contra o mal. A narrativa do íbex surge como uma ferramenta de instrução ao leitor, assim como a força do íbex deriva dos chifres que o animal tem, a força do homem resulta da leitura e do estudo dos Livros Sagrados (figura 1):

«"The Ibex symbolizes learned men, who are accustomed to shock-absorb whatever adversities befall them with a harmonization of the two Testaments, as if with some protecting breaking-action"3.

4 A narrativa do antílope tem também um propósito instrutivo e moralizante. Ao sentir sede, o antílope - simbolizando o homem - procura água no Rio Eufrates, à beira do qual encontra um arbusto com galhos finos. $O$ animal está preso nos galhos, entendidos como símbolos das tentações, tornando-se então vítima de caçadores - símbolos do diabo (figura 2). Mais uma vez, a forma de evitar tal destino é o conhecimento dos dois Testamentos:

"So it is with you, O man, who tries to be sober and chaste and to lead a holy life: the two Testaments serve you as two horns, with the help of which you can fell and root out all bodily and spiritual vices $[. . .]^{\prime 4}$. 
Figura 1: Íbex no Bestiário 12 CXIX, British Library, Royal MS 12 CXIX, f. 26r.

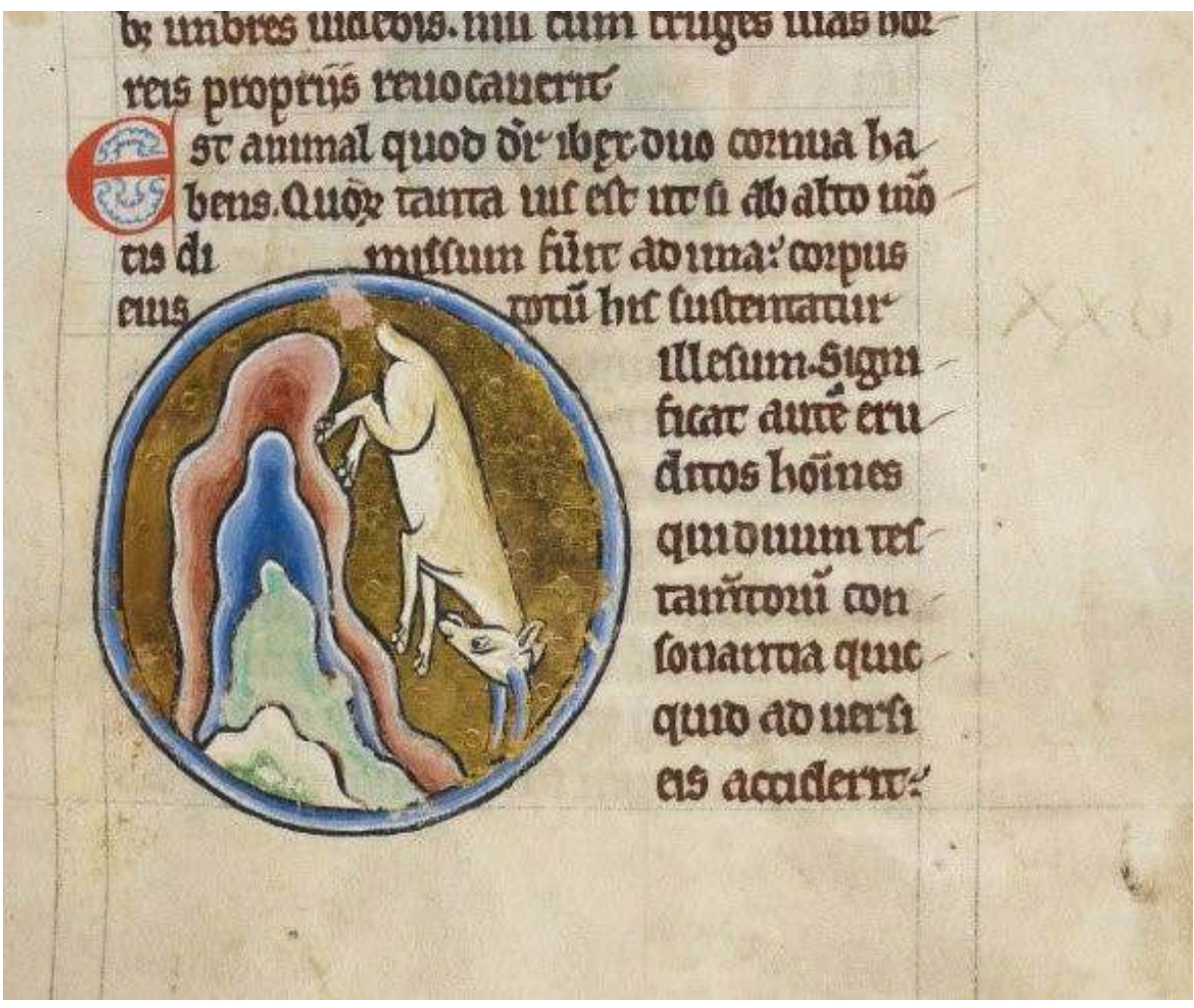

Figura 2: Antílope no Bestiário de Rochester, British Library, Royal MS 12 F XIII, f. 9v.

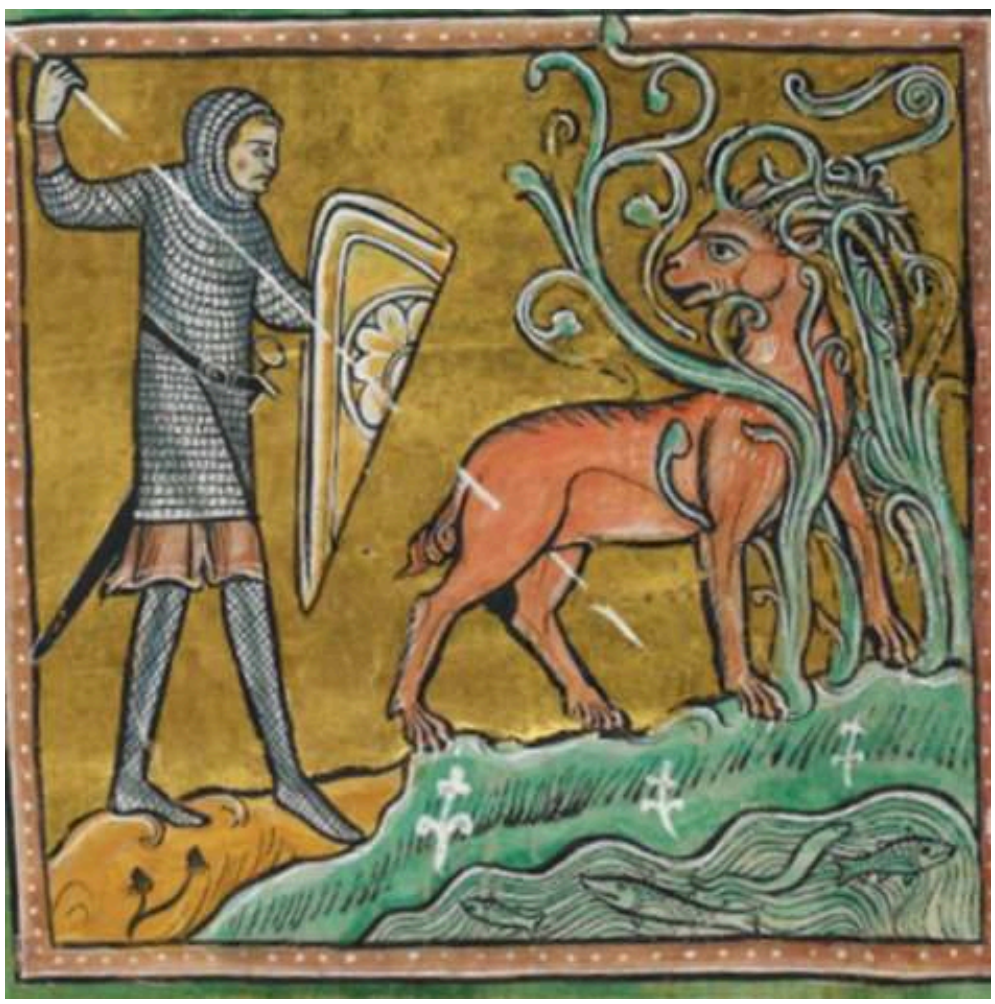

5 Além de expor os chifres como atributos de combate ao mal, as narrativas dos bestiários estabelecem, com bastante frequência, uma relação entre os animais que os possuem, 
Cristo e os fiéis da Igreja. Uma das mais constantes é feita a partir do sacrifício, como no caso dos bovinos. Na cultura Egípcia, ou na Greco-Romana, as figuras bovinas foram incorporadas nas representações de diferentes divindades, como Amón, o Touro celestial $^{5}$, e tais animais eram encarados especialmente como holocaustos. A Idade Média adaptou esses simbolismos de acordo com a doutrina cristã, convertendo os bovinos em signos, estabelecendo uma analogia com o sacrifício de Cristo. Todavia, à semelhança de muitos dos animais nos bestiários, outras atribuições simbólicas são possíveis e, por vezes, completamente opostas. O touro, por exemplo, em primeiro lugar pode representar Cristo pela associação à sua força: "Their fierceness is such that if they are captured they give up the ghost. The bull is Christ". . Por outro lado, pode ainda representar o orgulho dos príncipes: "Elsewhere bulls are the princes of this world, tossing the commom people on the horns of their pride" , tal como os búfalos, que também representam o orgulho.

É, contudo, o aspecto sacrificial o mais discutido nos trechos dos bovinos dos bestiários. Cristo aceitou o seu sacrifício, tal como os bovinos: "Augustine, the holy father, when he discusses the symbols of the Evangelists, calls the Lord Himself a calf, who offered Himself as a sacrifice for the salvation of the rest" ${ }^{\text {. }}$. De igual modo, a narrativa da vaca evidencia a função sacrificial dos bovinos e pode ser associada ao sacrifício de Cristo:

[...] the cow, which stands for the sacrifice of the Lord's incarnation in His weakness, of which it is written: "For though He was crucified through weakness, yet He liveth by the power of God" (II Corinthians 13:4) ${ }^{9}$.

7 Como sacrificiais podem ser encarados determinados ovídeos. 0 rebanho da Igreja - o carneiro, a ovelha e o Agnus Dei -, pela sua natureza calma, simbolizaram o sacrifício em diferentes tradições, designadamente na cultura hebraica - Hebreus, povo pastor -: "Imolarás o carneiro, tomarás seu sangue e o jogarás sobre o altar, todo ao redor" Durante a Idade Média, passaram a representar o sacrifício maior: o de Cristo, "o Cordeiro de Deus, que tira o pecado do mundo"11, aquele que, de forma mansa, "se deixou imolar como uma ovelha em prol da humanidade"12. Já Cristo, enquanto sacrifício, é simbolizado pelos ovídeos. No entanto, quando assumida posição de líder espiritual, é representado não pelo rebanho, mas pelo pastor, "O Bom Pastor". Através do discurso de São João, Jesus reconhece: "Eu sou o bom pastor: o bom pastor dá a sua vida pelas ovelhas"13 e, neste cenário, o rebanho é constituído pelos fiéis: “The sheep in the Gospels are the faithful [...]"14, que seguem seu líder: "As minhas ovelhas escutam a minha voz, eu as conheço e elas me seguem" ${ }^{15}$ (Figura 3). 


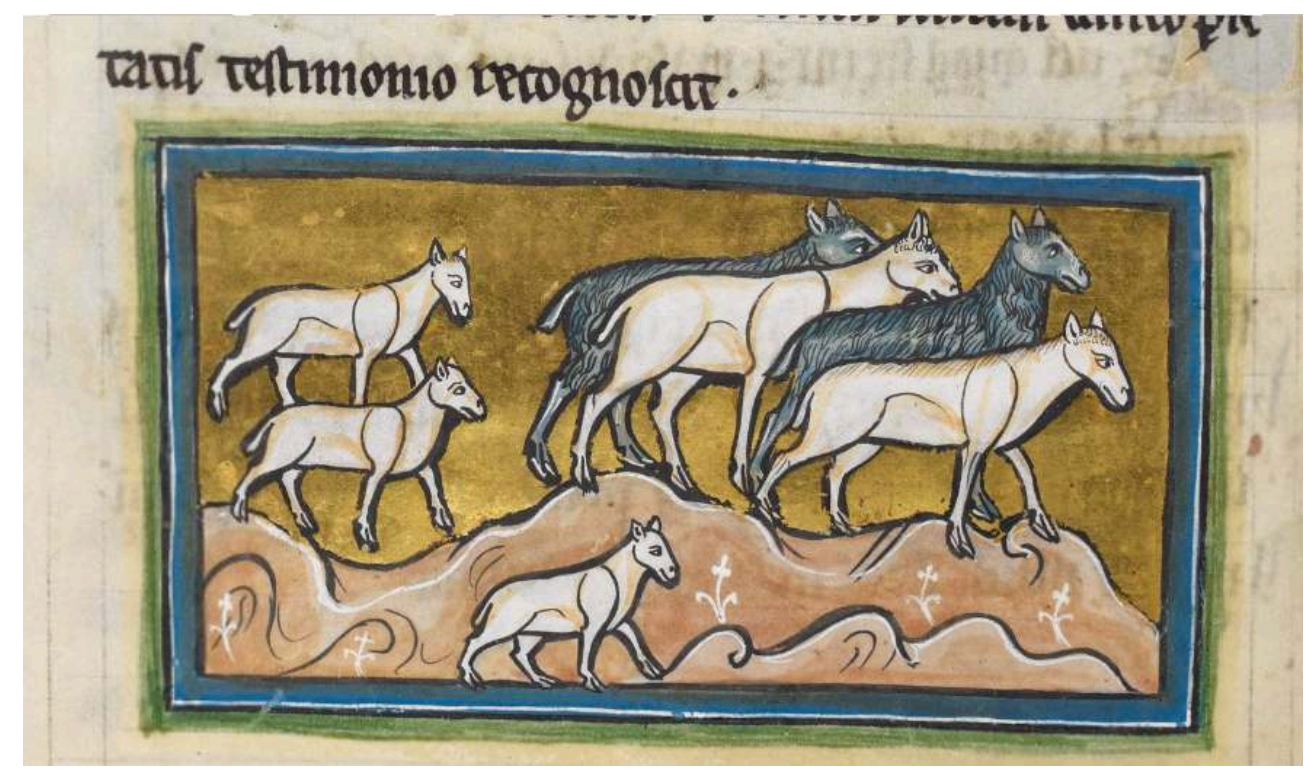

8 Cristo, em diversos bestiários, também foi representado como "The Holy Goat"16, ou seja, a figura da cabra e a da cabra selvagem, usando como artifício a visão aguçada destes animais: "Because the sharpness of a goat's eyes is very acute, and they see everything and know men from afar, this symbolizes Our Lord, who is the Lord God of all knowing"17.

9 À semelhança dos bovinos e ovinos, o unicórnio também pode ser encarado como uma figura sacrificial e como animal crístico, já que a sua alegoria se baseia na história da caça ao animal, aproximando-se simbolicamente do sacrifício de Cristo. Combinando as tradições clássicas - nomeadamente as descrições de Ctesias de Cnido (século V a.C.), Estrabão (65 a.C.-23 d.C.), Plínio, Solino, entre outros -, com a tradição hebraica (remetendo para as passagens bíblicas do animal de nome re'em, traduzida para o grego como monoceros ${ }^{18}$ ) e com as narrativas do Physiologus, os bestiários expõem o unicórnio como um dos animais mais importantes do imaginário da Idade Média. Fundamentando-se nas narrativas clássicas, os bestiários argumentam que o unicórnio não pode ser capturado com vida. Todavia, existem métodos para o seu aprisionamento:

A virgin girl is led to where he lurks, and there she is sent off by herself into the wood. He soon leaps into her lap when he sees her, and embraces her, and hence he get caught ${ }^{19}$.

$\mathrm{Na}$ interpretação mais frequente da fábula, o seio da virgem representa a Igreja e o poder de atração que esta exerce, e a virgem representa Maria - geralmente representada com um manto azul por cima de uma túnica vermelha (Figura 4). o Bestiário Bodley 764 refere que:

"He descended into the Virgin's womb to save us. He is called an insignificant creature because He humbled Himself in the flesh: He Himlsef said: "Learn of me, for I am meek and lowly in heart" (Matthew 11:29) ${ }^{20}$.

Esta obra também estabelece uma relação explícita entre o unicórnio e Cristo: "Our Lord Jesus Christ is the spiritual unicorn of whom it is said: "My beloved is like the son of the unicorns" (Ct, 2:9)"21. Como símbolo da união e unidade entre Deus e Cristo, o chifre do unicórnio torna-se o chifre da salvação: “The single horn on the unicorn's head signifies what He Himself said: "I and my Father are one" (John 10:30)" 22 . Assim, 
como símbolo da cruz de Cristo $^{23}$, o chifre do unicórnio também se relaciona com os chifres do íbex e do antílope, no sentido em que ambos podem ser entendidos como elementos de combate ao mal e ao diabo.

Figura 4: Unicórnio no Physiologus de Berna, século IX, Bern, Burgerbibliothek, Cod. 318, f. 16v.

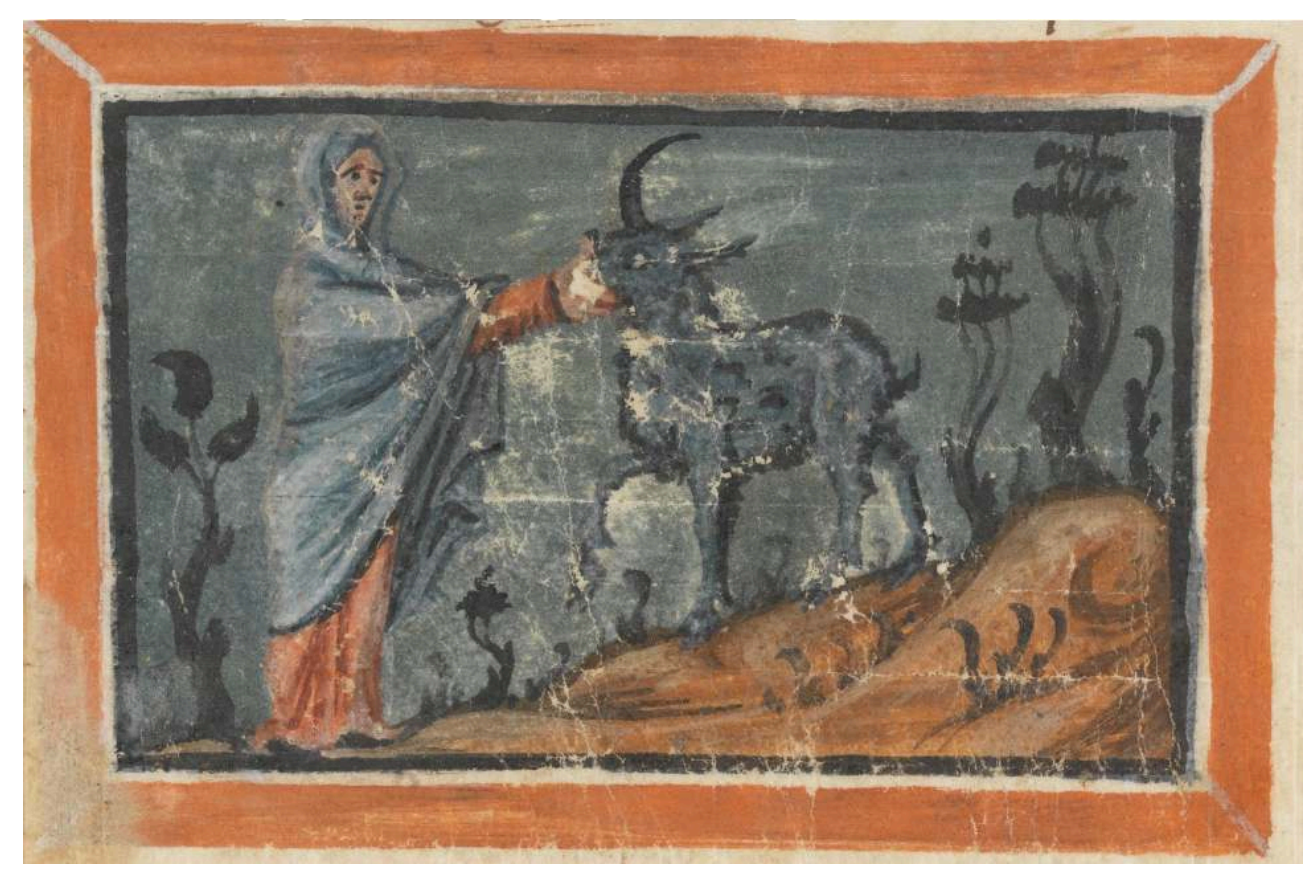

12 Outro animal crístico de extrema importância para o imaginário medieval é o cervo, animal na condição de agente psicopompo, designadamente em histórias de santos como as de Santo Eustáquio (?-118) (Figura 5), Santo Huberto de Liège (656-727) e São Juliano (séc. I). Os bestiários estabelecem uma comparação entre o comportamento do animal e Cristo a partir da relação entre o cervo e as serpentes ou dragões, estes entendidos como símbolos do diabo. O Bestiário de Cambridge indica o seguinte:

These creatures are enemies to serpents. When they feel themselves to be weighed down by illness, they suck snakes from their holes with a snort of the nostrils and, the danger of their venom having been survived, the stags are restored to health by a meal of them ${ }^{24}$. 
Figura 5: Santo Eustáquio no Decreto de Smithfield, Toulouse, 1300-1340, Royal MS 10 E IV, f. 230r.

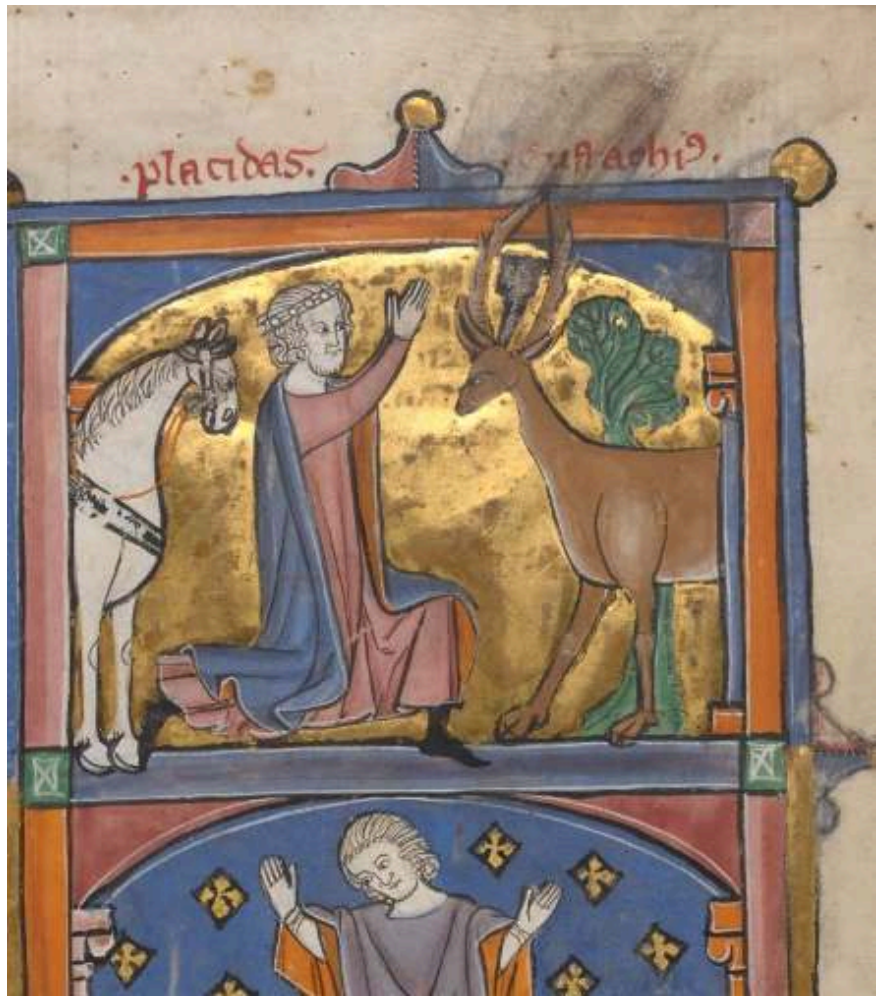

Além de simbolizar um mensageiro de Cristo nas histórias epifânicas de santos e de poder ser a representação do próprio filho de Deus, o cervo é, também, simbolicamente associado aos membros da Igreja. O Bestiário Bodley 764 sugere que os cervos gostam, por natureza, de procurar novas pastagens e de se mudarem, ajudando-se entre si na jornada $^{25}$. É neste sentido que os encontramos associados à atitude dos membros da Igreja:

[...] because while they change their homeland, that is, the world, for love of the heavenly homeland, they carry each other, that is, the more perfect bring on and sustain the less perfect by their example and their good works ${ }^{26}$.

Como indicado, nos bestiários medievais vários dos animais com chifres são representações consideradas positivas sob o ponto de vista da Igreja, simbolizando o fiel, os seus membros ou mesmo Cristo. Porém, nestes documentos, os animais com chifres podem também ser entendidos como animais ora ambíguos, ora símbolos do pecado. Ambíguos parecem ser os casos das narrativas do touro e do búfalo, como já explicitado, mas também o do cabrito, que por vezes simboliza Cristo: "Christ is like a kid because of the sins of the flesh" ${ }^{27} \mathrm{e}$, por outras, os pecadores: "They represent sinners, who shall stand on the left hand of God on the Day of Judgement" ${ }^{28}$. Do mesmo modo, o unicórnio, num primeiro momento encarado como símbolo crístico, possui significações negativas dependendo do contexto. $\mathrm{O}$ animal é símbolo da morte na história dos santos Barlaão e do príncipe indiano Josafá, compilada por João Damasceno (675-749) que persegue aqueles "que cobiçam os deleites corporais e deixam sua alma morrer de fome"29. E por poder representar o destino daqueles são seduzidos pelos prazeres do mundo, o unicórnio também se relaciona com a vaidade, lembrando a atuação da sereia. 

o animal com chifres dos bestiários medievais que mais se aproxima da ideia do pecado, do pecador e do diabo, podendo ser associado aos judeus. Nos bestiários, é a conotação sexual do bode que se destaca nas suas narrativas (Figura 6). 0 sangue quente do animal, aquecido pelo vício carnal, é a única substância da natureza capaz de dissolver o diamante, pedra que afasta os espíritos demoníacos, de acordo com lapidários medievais. Por esta característica, o bode torna-se, alegoricamente, o pecador: "For the he-goat, [...], shows us the sinner, who is pouring out his blood (that is, in the tears of penitence) dissolves the hardness of his sins" ${ }^{30}$. O MS Bodley 764 apresenta de forma clara o simbolismo do bode como um pecador que se entrega à luxúria e completa: "The goats are the sinners of Gentiles. [...] The he-goats are those who follow the depravities of the devil and clothe themselves in the shaggy hide of vice"31.

Figura 6: Bodes no Rochester Bestiary, British Library, Royal MS 12 F XIII, f. 36r.

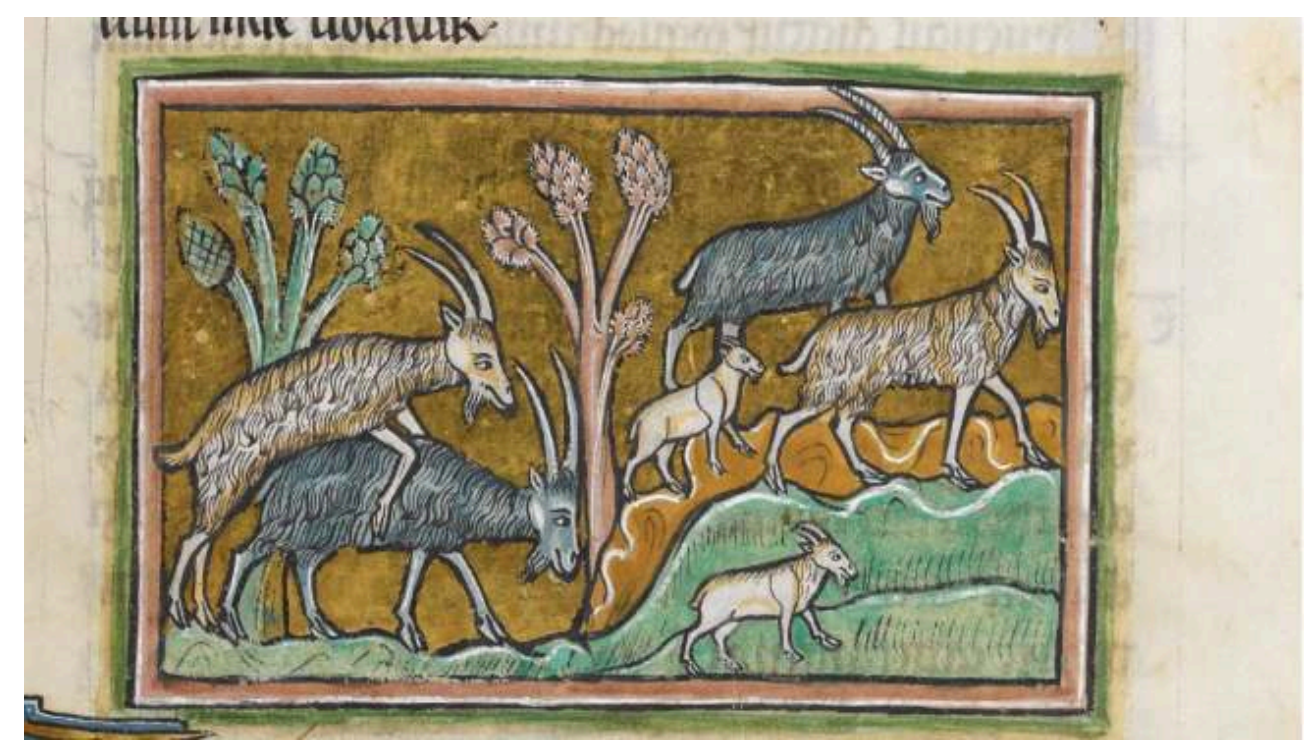

\section{Considerações finais}

Depois da análise das narrativas dos manuscritos medievais e das obras que inspiraram as criações dos mesmos, pode considerar-se que os chifres e animais com chifres tornaram-se elementos de grande importância simbólica no imaginário medieval. Mesmo que adaptados a uma função doutrinária e edificante proposta pelo Cristianismo deste período, parece que os simbolismos dos animais com chifres possuem mais permanências do que rupturas em relação aos significados na Antiguidade. O facto de os chifres se manterem como símbolos relacionáveis com o poder parece comprová-lo. Veja-se o caso da pantera, um animal que não possui chifres na natureza, mas que os adquire a fim de poder ser associado à força de Cristo, "the true panther" ${ }^{32}$. Ilustrar a pantera com chifres não surge enquanto escolha estilística, ou como resultado de um erro dos iluminadores dos bestiários. É um elemento simbólico, que evoca poder, aqui espiritual (Figura 7). 
Figura 7: Pantera no Bestiário Lat. 3630 (BnF, lat. 3630, f. 76r).

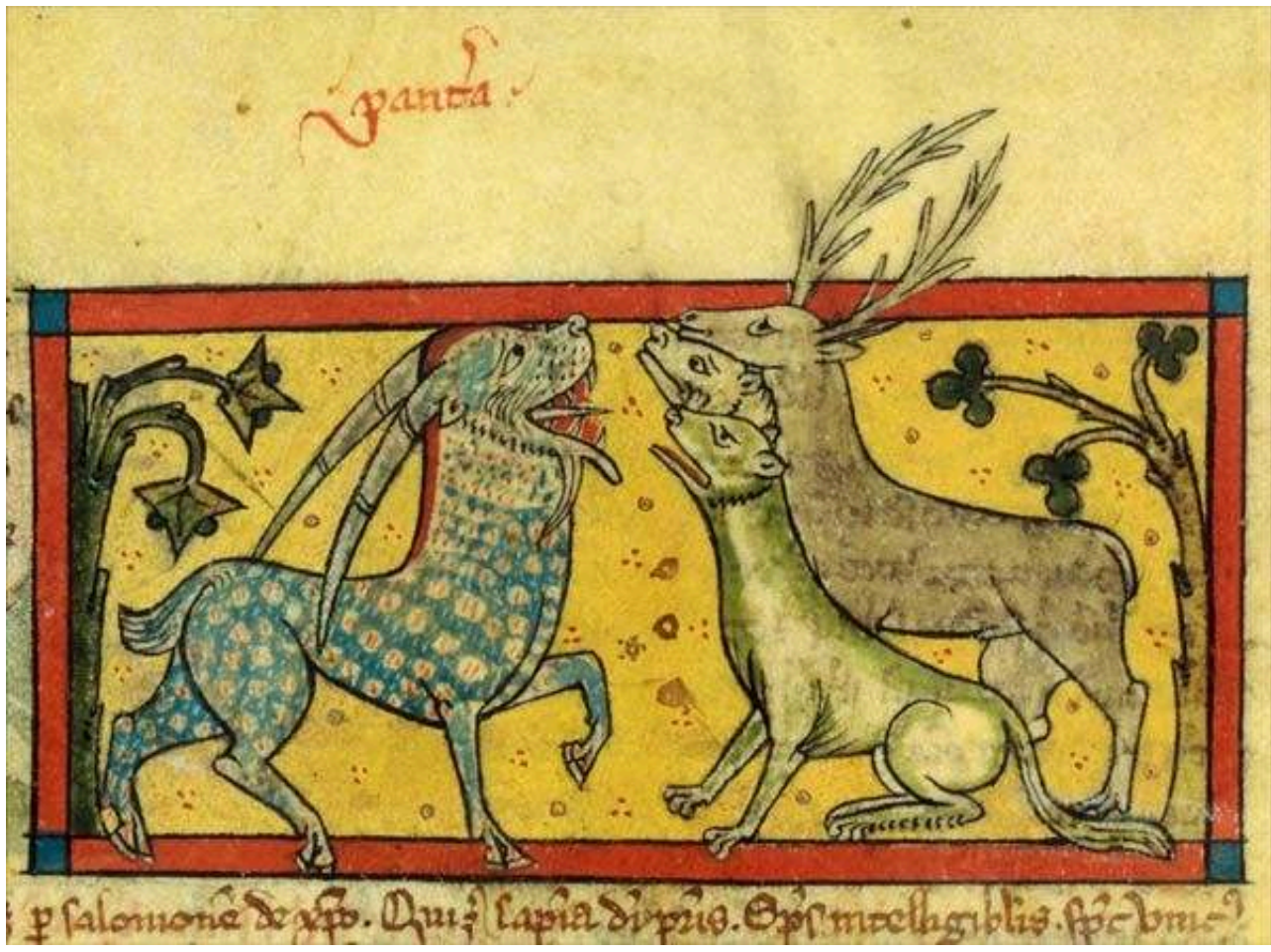

Ainda que muito ligados ao poder, os chifres não podem ser encarados como forma de individualizar simbolicamente os animais que os possuem. Tal justifica-se, como vimos, através do amplo espectro simbólico atribuído aos animais chifrudos e aos chifres. Numa primeira abordagem, um animal como o unicórnio parecia ser um emblema exclusivamente positivo durante a Idade Média, enquanto o bode aparentava ser unicamente negativo. No entanto, a mentalide medieval recorreu a diferentes tradições para compor as narrativas alegóricas animais e, por isso, tais alegorias são passíveis de várias interpretações dependendo dos seus contextos e da finalidade de cada texto produzido. Assim, o unicórnio pode simbolizar Cristo a partir do seu sacrifício e do poder atrativo exercido pela Virgem, mas pode também ser símbolo da vaidade, do amor cortês e, até, da morte, como no caso da história dos Santos Barlaão e Josafá. o bode, por sua vez, relaciona-se com o pecador, com a luxúria, com os desvios morais, mas também pode ser associado à fertilidade.

\section{NOTAS}

1. MELLINKOFF, Ruth - The horned Moses in Medieval Art and Thought. Berkeley, Los Angeles, London: University of California Press, 1970, p. 76.

2. HUMPHREYS, H. - "The horn of the unicorn". Antiquity 27 (105), (1953), pp. 15-19.

3. Cambridge University Library, MS l.i. 4. 26. The Book of Beasts. Ed. e Trad. T. H. White. New York: Dover Publications, 1984, p. 29. 
4. Oxford, Bodleian Library, MS Bodley 764. Bestiary. Ed. Richard Barber. Woodbridge: The Boydell Press, 1999, p. 34.

5. CHARBONNEAU-LASSAY, Louis - The Bestiary of Christ. New York: Parabola Books, 1991, p. 55.

6. MS Bodley 764. Bestiary. Ed. Richard Barber, p. 88.

7. MS Bodley 764. Bestiary. Ed. Richard Barber, p. 89.

8. MS Bodley 764. Bestiary. Ed. Richard Barber, pp. 93-94.

9. MS Bodley 764. Bestiary. Ed. Richard Barber, p. 92.

10. Ex, 29:16. Edição consultada: Bíblia de Jerusalém. São Paulo: Paulus Editora, 2016.

11. Jo, 1:29. Bíblia de Jerusalém.

12. VARAZZE, Jacopo de - Legenda Áurea. Ed. e Trad. Hilário Franco Júnior. São Paulo: Companhia das Letras, 2003, p. 435.

13. Jo, 10:11. Bíblia de Jerusalém.

14. Oxford MS Bodley 764. Bestiary. Ed. Richard Barber, p. 78.

15. Jo, 10:27. Bíblia de Jerusalém.

16. MS l.i. 4. 26. The Book of Beasts. Ed. e Trad. T. H. White, p. 41.

17. MS l.i. 4. 26. The Book of Beasts. Ed. e Trad. T. H. White, p. 41.

18. HUMPHREYS, H. - "The horn of the unicorn", p. 377.

19. Bestiário Harley 4721. The Book of Beasts. Ed. e Trad. T. H. White, p. 21.

20. MS Bodley 764. Bestiary. Ed. Richard Barber, p. 37.

21. MS Bodley 764. Bestiary. Ed. Richard Barber, pp. 36-37.

22. MS Bodley 764. Bestiary. Ed. Richard Barber, p. 37.

23. LE GOFF, Jacques - Heróis e maravilhas da Idade Média. Petrópolis: Editora Vozes, 2011, pp. 141-142.

24. MS l.i. 4. 26. The Book of Beasts. Ed. e Trad. T. H. White, p. 37.

25. MS Bodley 764. Bestiary. Ed. Richard Barber, p. 51.

26. Aberdeen University Library, MS 24, f. $13 \mathrm{r}$ e f. 13v. Disponível em: https:// www.abdn.ac.uk/bestiary/ms24

27. MS Bodley 764. Bestiary. Ed. Richard Barber, p. 82.

28. MS Bodley 764. Bestiary. Ed. Richard Barber, p. 82.

29. VARAZZE, Jacopo de -Legenda Áurea. Ed. e Trad. Hilário Franco Júnior, p. 994.

30. MS Bodley 764. Bestiary. Ed. Richard Barber, p. 83.

31. MS Bodley 764. Bestiary. Ed. Richard Barber, p. 83.

32. MS Bodley 764. Bestiary. Ed. Richard Barber, pp. 30-31.

\section{AUTOR}

\section{MARCELO CARDOSO AMATO}

Instituto de Estudos Medievais, Faculdade de Ciências Sociais e Humanas, Universidade Nova de Lisboa, 1069-061 Lisboa, Portugal marcelocardosoamato@hotmail.com 